\title{
Desain Travel Bag Dengan Menggunakan Konstruksi Bambu Laminasi
}

\author{
Muhammad Fuadakbar Rahmatullah ${ }^{1}$,Agung Pramudya, S.Sn, M.Sn ${ }^{2}$ \\ 1.Jurusan Desain Produk, Fakultas Seni Rupa dan Desain ITENAS, Bandung \\ 2.Jurusan Desain Produk, Fakultas Seni Rupa dan Desain ITENAS,Bandung \\ Email: fuadakbar92@gmail.com
}

\begin{abstract}
Abstrak
Bambu adalah salah satu bahan baku ketersediaannya sangat tinggi di Indonesia, memiliki beberapa keunggulan dari sisi karakteristik material untuk dapat diterapkan pada produk. Tujuan penelitian ini adalah untuk menggali potensi bambu dengan teknik laminasi. Selama ini bambu dimanfaatkan sebagai material konstruksi pada bangunan dan berbagai macam furniture, akan tetapi bambu memiliki banyak potensi yang masih bisa digali, salah satunya adalah menjadi material konstruksi pada sarana bawa. Pada penelitian ini penulis melakukan eksplorasi bentuk bambu dengan teknik bending dan laminasi yang dimanfaatkan karakteristiknya sehingga dapat ditemukan potensi bambu laminasi yang cocok diterapkan untuk produk tas traveling. Semua riset dam eksplorasi mengenai analisis tersebut akan diangkat menjadi sebuah konsep dalam produk sarana bawa yang akan dirancang. Diharapkan melalui penelitian ini dapat dihadirkan nilai kebaruan desain pada tas travel bag melalui penggabungan material alam dan material buatan. Penelitian dilakukan sebagai acuan / sumber informasi /kajian teori / analisis data bagi proyek desain selanjutnya. Pada penelitian ini metode yang digunakan diawali dengan observasi,survey dan riset pada kegiatan traveling, baru kemudian dilakukan eksperimen penggunaan bambu sebagai kerangka. Jika penerapan dan teknik pengolahan material bambu di gunakan pada jenis tas travel yang tepat,maka akan munculnya kebaruan pada desain tas travel
\end{abstract}

Kata Kunci: Bambu,Laminasi ,Tas,Potensi,Travel

\section{Abstract}

Bamboo is one of the high availability raw materials in Indonesia, has several advantages in terms of material characteristics to be applied to the product. The purpose of this study was to explore the potential of bamboo using lamination techniques. So far, bamboo is used as construction material in buildings and various kinds of furniture, but bamboo has a lot of potential that can still be explored, one of which is to become a construction material for carrying facilities. In this study the authors explored the shape of bamboo with bending and lamination techniques that utilized its characteristics so that it can be found the potential of laminated bamboo suitable for traveling bag products. All exploratory dam research regarding the analysis will be appointed as a concept in the carrying facility product that will be designed. It is hoped that through this research, the novelty of design in a travel bag can be presented through the combination of natural and artificial materials. The study was conducted as a reference / source of information / theoretical study / data analysis for further design projects. In this study the method used begins with observation, survey and research on traveling activities, then an experiment is carried out using bamboo as a framework. If the application and processing technique of bamboo material is used on the right type of travel bag, there will be a renewal of the design of the travel bag

Keywords: Bamboo, Lamination, Bag, Potential, Travel

\section{Pendahuluan}

Bambu sangat potensial sebagai bahan substitusi kayu karena rumpunan bambu dapat terus berproduksi selama pemanenannya terkendali dan terencana (Arsad, 2015). Selain nilai ekonomis yang jauh lebih terjangkau dari material lain yang sejenis. Bambu memiliki waktu tumbuh yang cepat dibandingkan dengan kayu yang membutuhkan waktu puluhan tahun untuk dipanen dan diolah.

Pemanfaatan bambu di indonesia sudah sangat banyak diterapkan untuk dijadikan produk dengan beragam perlakuan serta teknik yang beragam. dengan adanya kemajuan teknologi pada saat ini,
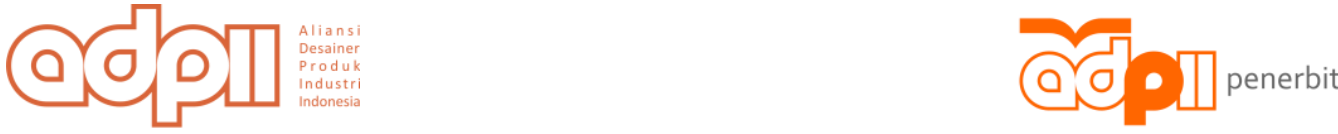


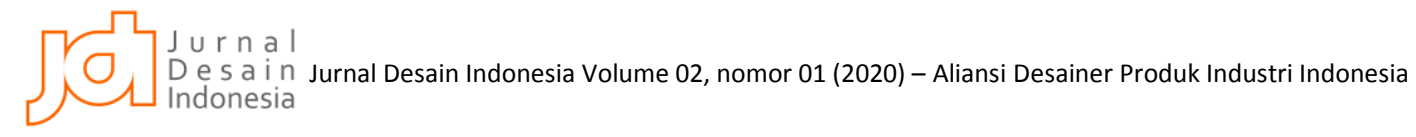

kualitas dan waktu produksi menjadi semakin baik dan cepat. Pengolahan bambu tergantung pada penggunaan atau pemanfaatannya. Selain untuk dimanfaatkan sendiri oleh masyarakat, produk olahan bambu sudah banyak diekspor keluar negeri seperti furniture, kerajinan/handycraft (Arhamsyah, 2009) terdapat beberapa bagian pada bambu yang dapat dimanfaatkan. Diantaranya batang, kulit, daging dan daun. Sifat komposit bambu mungkin properti yang paling umum digunakan sebagai hasil dari struktur anatomis yang unik dimana serat yang kuat disimpan dalam matriks resin, serat berorientasi sepanjang sumbu longitudinal dari batang silinder di dalam ruas (Madhavi K, 1994)

Bambu memiliki beberapa karakter yang dapat dimanfaatkan sesuai kebutuhan produk,sesuai dengan Page | 52 kebutuhan dan spesifikasi produk yang akan di buat. Terdapat beragam karakter yang menjadikan pemanfaatan bambu saling berbeda satu sama lain. Beberapa jenis bambu memiliki ketahanan yang tinggi sehingga sangat cocok digunakan sebagai produk-produk yang konstruktif, beberapa jenis bambu lain memiliki kelenturan yang tinggi, dan beberapa lagi memiliki diameter yang cukup besar. Dengan demikian tidak semua jenis bambu sesuai untuk bahan baku kerajinan atau produk-produk yang menonjolkan aspek estetik. Beberapa jenis bambu yang dianggap cocok untuk keperluan itu, antara lain adalah bambu apus, bambu ater, bambu betung, bambu gombong, serta bambu hitam. Umur pakai yang relatif singkat mempengaruhi nilai ekonomis produk berbahan baku bambu. Beberapa faktor yang mempengaruhi umur pakai ini, antara lain umur saat tebang, kandungan pati, cara penyimpanan, iklim, dan serangan organisme perusak, seperti bubuk kayu kering,jamur, dan rayap (Masri, 2015). Maka dari itu pemanfaatan bambu laminasi sebagai bahan baku produk bisa menjadi peluang sebagai pengganti material yang digunakan secara overused.dan berpeluang sebagai komponen pada tas travel pada penelitian ini. Jika penerapan dan teknik pengolahan material diimplementasikan pada jenis tas travel yang tepat,maka akan adanya suatu kebaruan pada salah satu aspek penunjang pada desain tas travel.

\section{Metodologi}

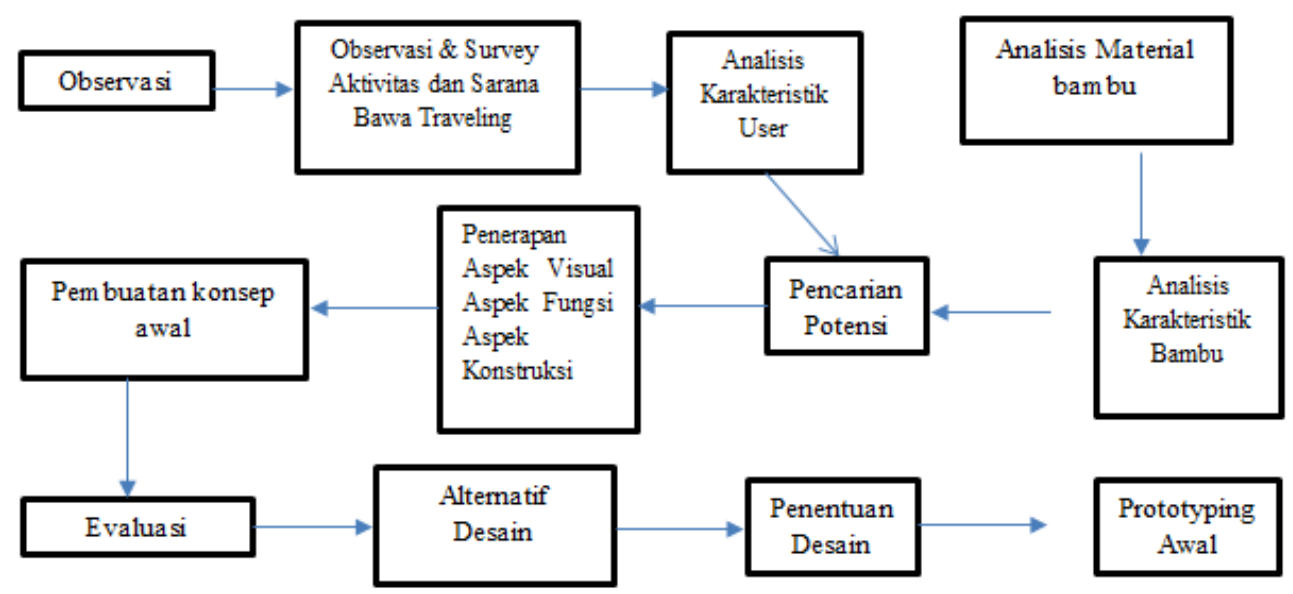

Bagan 1. Proses desain yang dilaksanakan
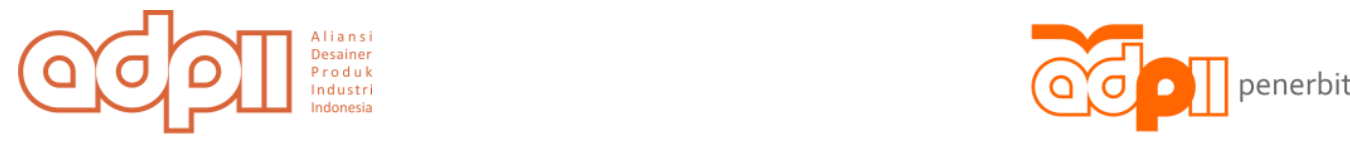

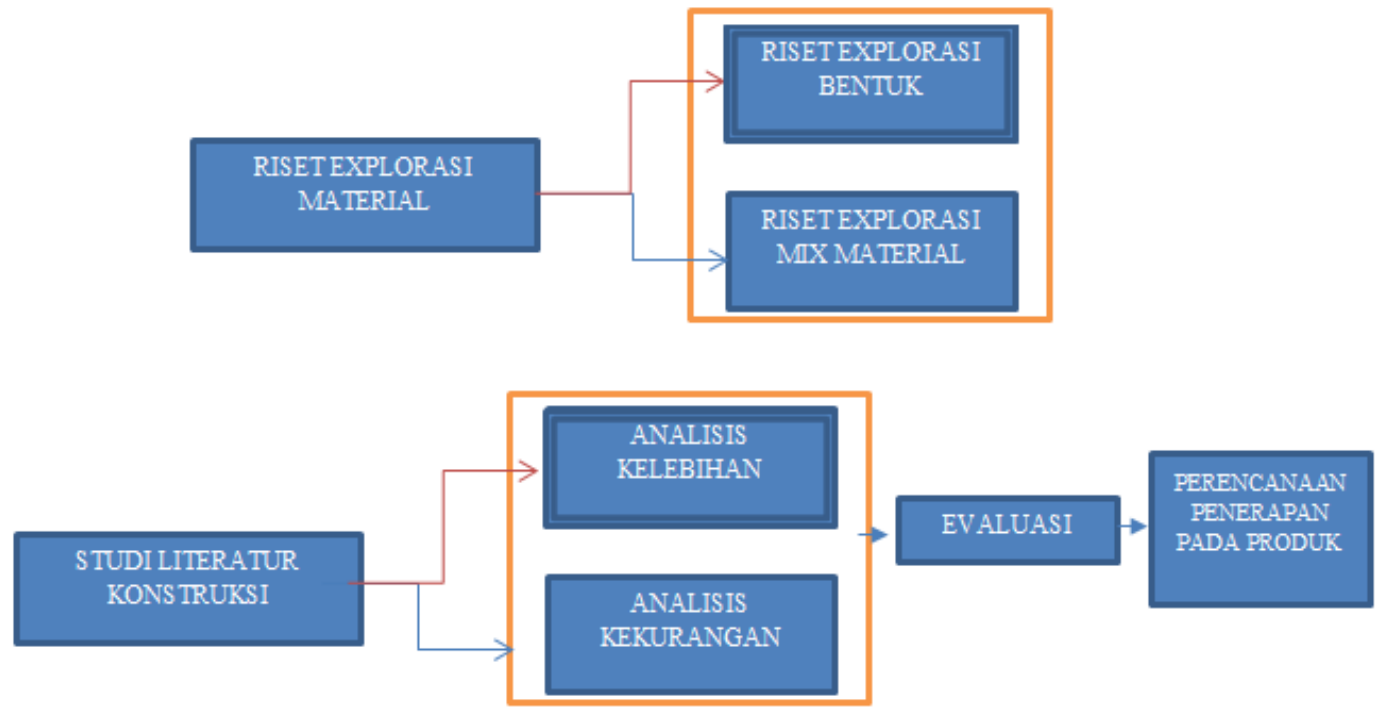

Bagan 2 Pemikiran yang dilaksanakan

Pada penelitian kali ini penulis melakukan observasi dan survey dengan metode wawancara dan membuat kuisioner untuk beberapa responden yang berkaitan dengan aktivitas traveling, output dari wawancara dan kuisioner adalah kesimpulan yang di analisis untuk pencarian potensi.setelah melakukan observasi penulis melakukan riset explorasi bentuk dengan pendekatan "Design by Doing" untuk mencari potensi bentuk yang cocok serta mempertimbangkan aspek aspek material bambu yang akan di terapkan pada produk,Penulis juga menggunakan metode studi literatur untuk menemukan solusi desain.studi literatur diperlukan untuk mendapatkan gambaran penelitian yang sudah dilakukan sebelumnya. Sumber yang digunakan sebagai studi antara lain dari desain konstruksi yang sudah dibuat sebelumnya. Data yang diperoleh dari sumber tersebut untuk selanjutnya dilakukan analisis dengan menjabarkan kelebihan dan kekurangan secara deskriptif.

\section{Pembahasan}

Pada hasil penelitian penulis mencari potensi karakteristik bambu yang tepat di aplikasikan pada desain Backpack travel,saat ini kegiatan travel begitu digemari kalangan remaja serta keluarga untuk mengisi waktu libur di sela sela kesibukan sehari hari. Tujuan kegiatan traveling adalah sebagai media liburan dan refreshing. (Heru, 2016) tujuan traveling pada umumnya ke tempat tempat wisata untuk mengenal suatu tempat yang dikunjungi atau sekedar mendokumentasikan perjalan untuk di muat pada akun sosial media nya. Hasil studi GTIS 2015 memperlihatkan dari sisi frekuensi perjalanan, ternyata orang Indonesia juga ingin lebih sering bepergian, diperkirakan orang Indonesia akan mengambil rata-rata lima perjalanan dalam dua tahun ke depan, lebih banyak dari rata-rata global yaitu tiga perjalanan. Dari sisi lama tinggal, ada peningkatan sebesar sembilan persen, di mana 30 persen responden ingin bepergian lebih dari tujuh hari, dari sebelumnya hanya 21 persen. (Heru, 2016)

Untuk menunjang kegiatan traveling membutuhkan sarana bawa yang sesuai dengan aktivitasnya. sarana Bawa (Tas) untuk traveling tersedia dalam berbagai pilihan model dan juga ukuran, mulai dari model ransel, pinggang, ataupun slempang. Hanya saja, untuk model ransel bisa digunakan untuk menyimpan berbagai perlengkapan travel dengan ukuran yang lebih besar serta banyak.
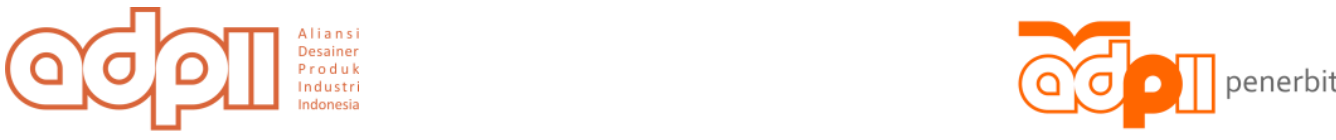

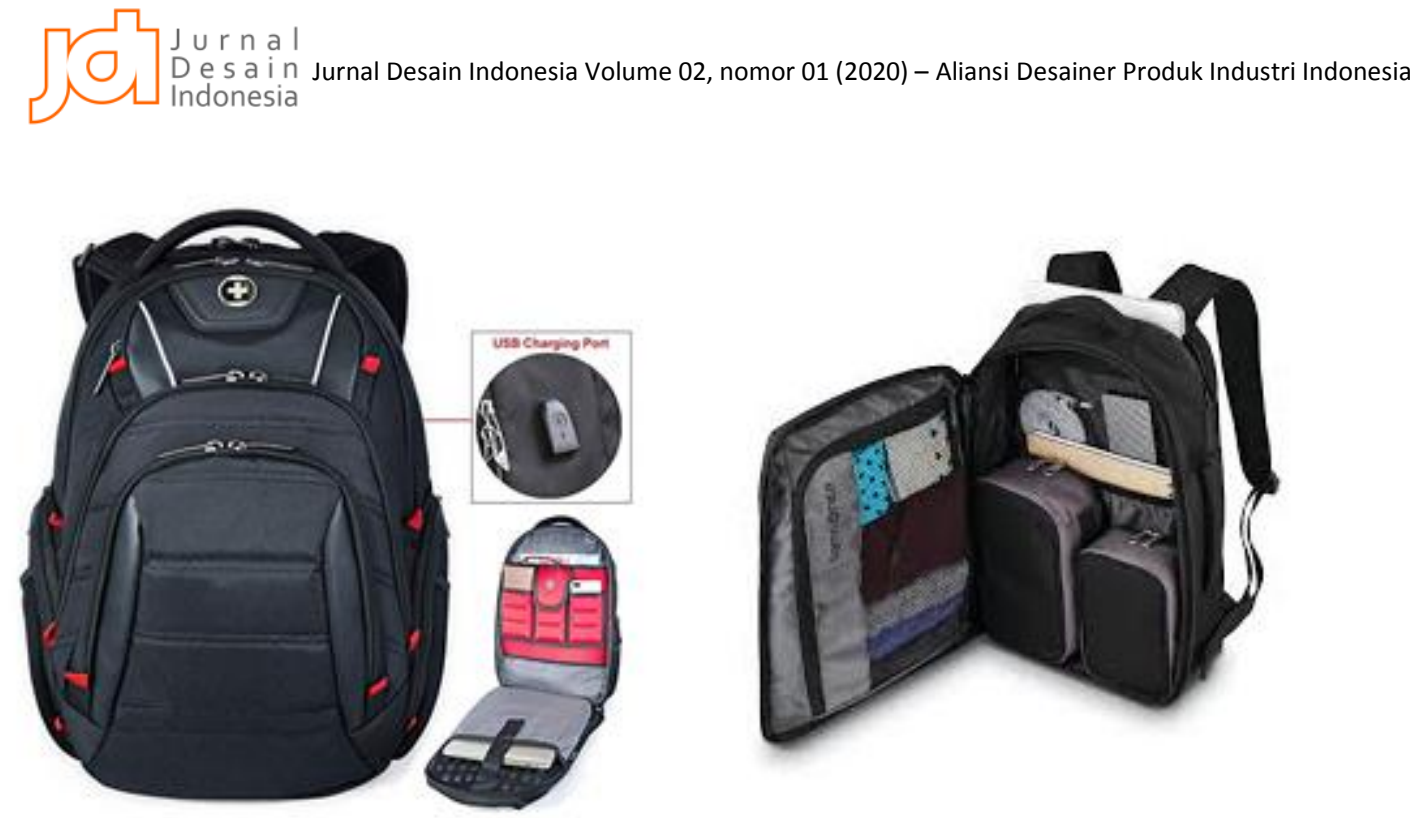

Page | 54

Gambar 1. Jenis travel Backpack (sumber: https://www.amazon.com/Business-Travel-Backpack-BackpacksLaptops/dp/B07YYSGFVJ)

Pada umumnya tas travel bervolume lebih dari $30 \mathrm{~L}$ untuk menunjang kebutuhan pemakainya, tapi tidak menutup kemungkinan tas travel bervolume lebih kecil karena disesuaikan dengan durasi perjalanan yang akan dilakukan traveler. Tas travel menggunakan system zipping 270 derajat untuk memudahkan membuka akses kompartemen utama ,kebanyakan tas travel menggunakan material yang ringan karena membutuhkan mobilitas tinggi sehingga tidak membatasi aktivitas user karena beban yang ditanggung pada badan user,akan tetapi karena menggunakan material yang ringan, adanya dampak terhadap bentuk tas travel pada aspek visual dan fungsi, sehingga penulis menyimpulkan bahwa tas travel membutuhkan konstruksi agar dapat mempertahankan bentuk tas travel dan proteksi terhadap barang bawaan user dari benturan dan cuaca. Maka untuk mendapatkan pengalaman traveling yang nyaman dan berkesan, maka wajib untuk memanfaatkan berbagai perlengkapan. Gadget (Handphone,Camera,Laptop) adalah beberapa barang wajib ketika melakukan perjalanan, tapi bendabenda seperti tas traveling yang biasa dianggap sepele juga harus disesuaikan sesuai kebutuhan dan jenis perjalanan yang dilakukan.

\section{KLASIFIKASI TRAVELER}

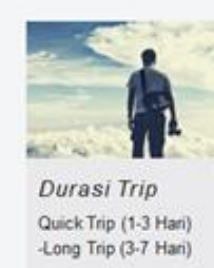

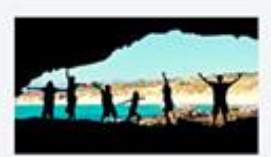

User

Destinasi

Kelompok

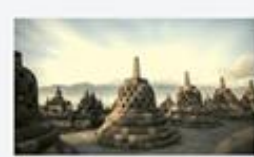

Dalam Negeri Luar Nogen

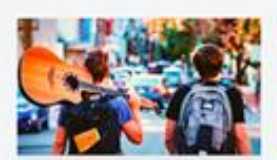

Kebutuhan spesifik

Traveler berdasarkan kebutuhan spesifik
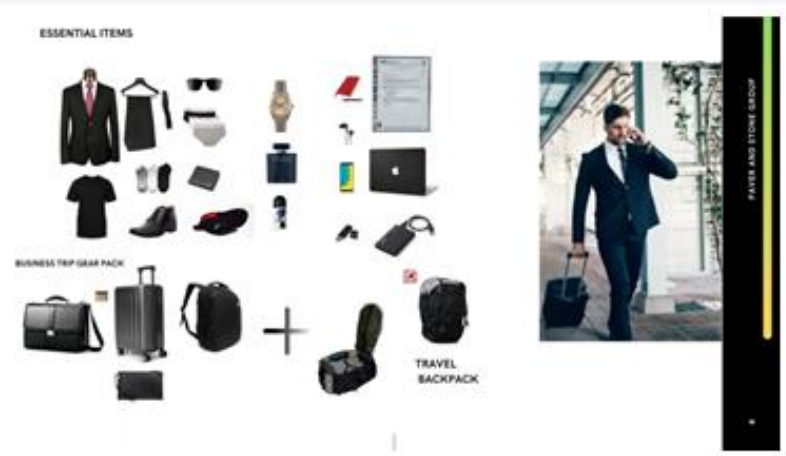

Gambar 2. Klasifikasi Traveler menurut penulis
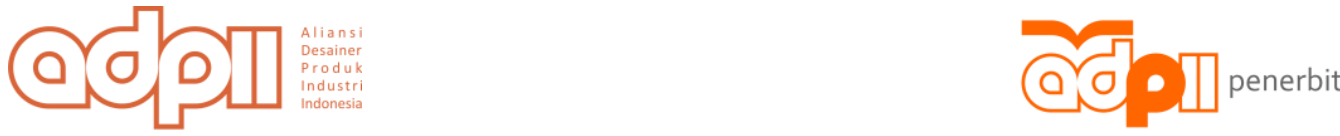
Sebelum proses perancangan dan pencarian ide, penulis melakukan wanwancara dan survey terkait barang bawaan user ketika melakukan traveling. Setelah melakukan keduanya, selanjutnya penulis membuat sebuah presentasi yang mengklasifikasikan beberapa traveler, luaran dari presentasi adalah penetepan traveler yang akan di kaji kriteria ,dan karakteristik traveler.Batasan jenis traveler yang dikaji adalah traveler yang melakukan business trip sehingga muncul batasan-batasan visual serta fungsi produk untuk mengakomodir kegiatan business trip.

Penulis menggunakan bambu sebagai konstruksi tas karena dengan adanya konstruksi maka dapat Page | 55 mempertahankan bentuk tas serta mampu menjadi proteksi barang bawaan pada tas terhadap benturan dan goncangan. Bambu memiliki potensi untuk dimanfaatkan sebagai konstruksi karena memiliki karakteristik yang kokoh. Bambu memiliki kekuatan dan kekakuan bahkan dapat melebihi material lain. Bambu bisa lebih kuat dari beton dalam aspek kompresi atau tekan, yang merupakan sifat struktural yang baik untuk penggunaan konstruksi. Sifat mekanik bambu yang paling penting adalah memiliki kekuatan yang sama bahkan lebih tinggi dalam perbandingan atau rasio dengan material baja pada aspek ketegangan/kekakuan, yang ideal untuk penggunaan dalam konstruksi kerangka / rangka. (Suriani, 2017)
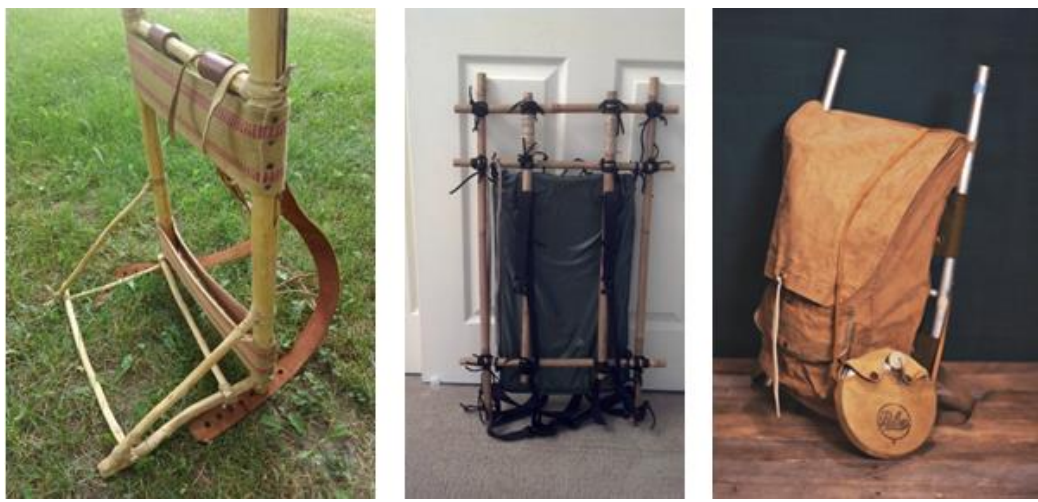

Gambar 3. Ragam Kerangka yang sudah ada di pasaran

Gambar kiri adalah bentuk Kerangka rangka Eksternal alat bawa konvensional.

Gambar tengah adalah bentuk Kerangka rangka Eksternal yang dengan material fabric.

Gambar kanan adalah bentuk Kerangka rangka Eksternal Backpack

\subsection{ANALISIS}

Pada gambar 3 kerangka rangka pada alat bawa konvensional memiliki struktur yang kokoh dengan mengkombinasikan material bambu dan kayu, jointing yang diterapkan menggunakan sistem jointing ikat pada setiap pertemuan sisi .adanya masalah yang muncul pada aspek ergonomi konstruksi karena tidak adanya back system sehingga mengurangi kenyamanan ketika dipakai.

Pada gambar tengah, konstruksi kerangka eksternal keseluruhan menggunakan bambu dengan jointing ikat pada penyatuanya. Konstruksi rangka di masukan pada celah (tidak permanen) yang dibuat pada bahan kain sehingga kain dapat dilepas ketika rangka membutuhkan reparasi atau perawatan. Akan tetapi kerangka yang menonjol keluar dapat mengganggu kenyamanan pemakai, dan dan rawan membentur objek sekitar pemakai.

Pada gambar kanan, kerangka eksternal direkatkan pada backpack menggunakan sekat jaitan pada tiap sisi belakang backpack sehingga kerangka dapat di lepas pasang ketika tidak dibutuhkan akan tetapi mengganggu visual pada backpack.
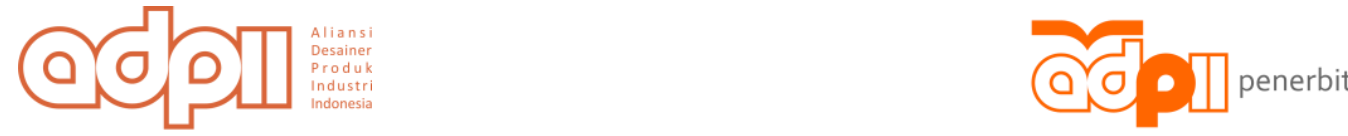


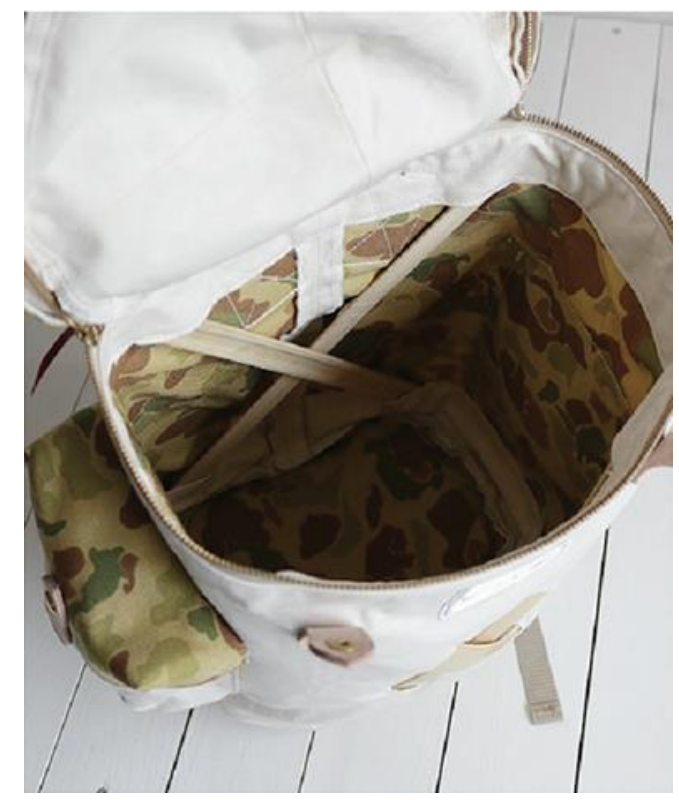

Pada gambar diatas, konstruksi dalam pada backpack menggunakan bambu yang disilang, berfungsi untuk mempertahankan bentuk tas dan memperbesar dimensi tas. Kerangka yang digunakan dapat dilepas untuk keperluan perawatan pada bambu. Dengan penerapan kerangka di dalam tas Backpack ,visual pada bagian luar tidak terganggu. Sehingga bisa menjadi solusi yang tepat simple dan efektif.
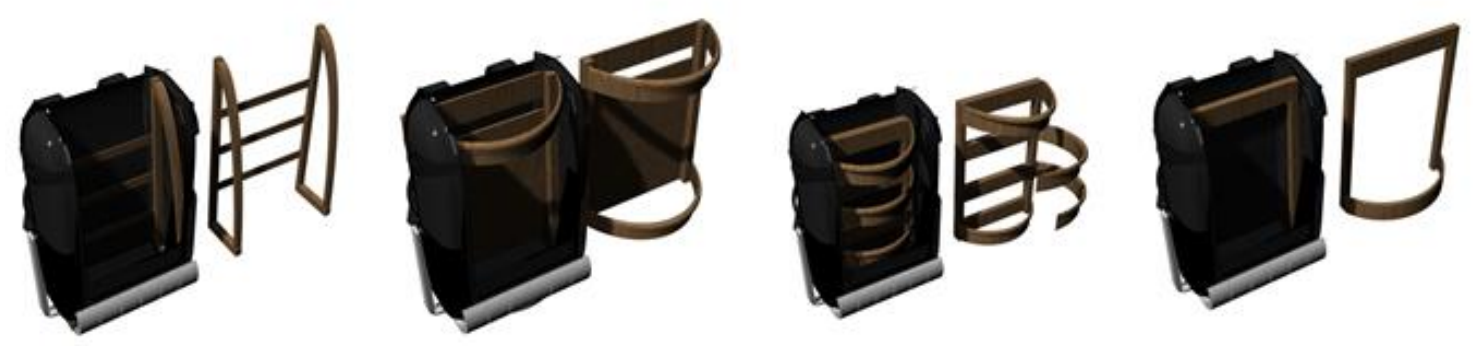

Gambar 5. Alternatif perencanaan explorasi bentuk kerangka rangka dalam Backpack

\subsection{Explorasi}

Eksplorasi yang dilakukan penulis tentang pencarian bentuk dengan menggunakan metode learning by doing. Pada tahapan pertama penulis menganalisis bentuk tas travel yang akan diberikan konstruksi pada bagian dalamnya.

Analisis yang dilakukan mengenai penempatan konstruksi/rangka/kerangka yang akan di tempatkan pada bagian tas. Penetapan konstruksi antara lain pada bagian samping , bawah dan atas tas.

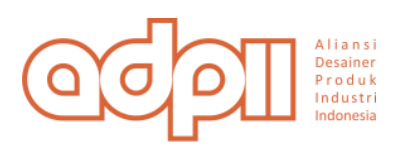



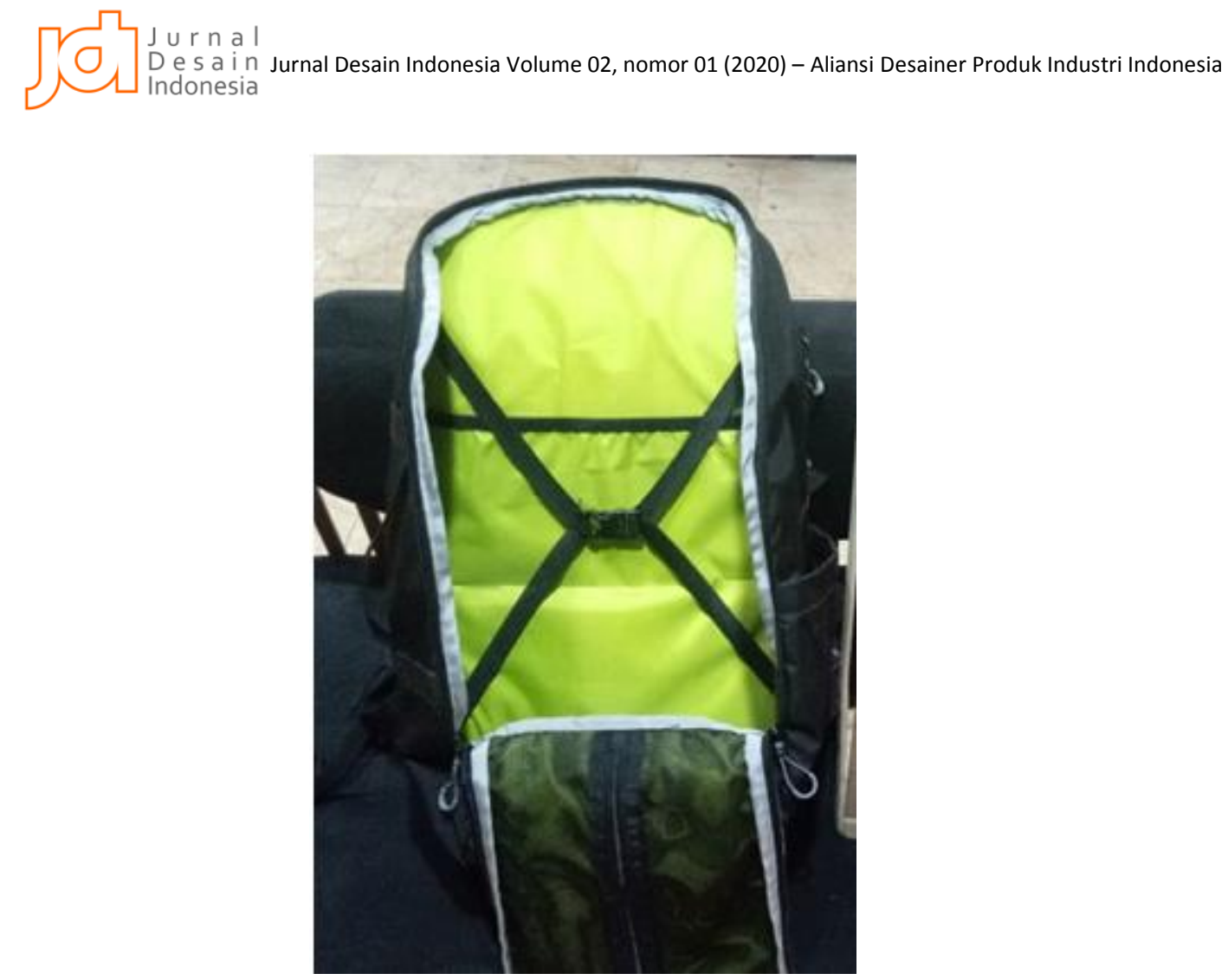

Page | 57

Gambar 6. Bagian dalam tas trave

Selanjutnya penulis membuat molding dengan menggunakan material MDF sebagai alat cetak untuk melakukan teknik bending pada bambu. Pada bagian samping tas menggunakan teknik bending. Teknik bending dilakukan agar konstruksi bambu mengikuti bentuk radius pada bagian yang memiliki kurva, sehingga konstruksi dapat merekat dengan baik dan kokoh sesuai bentuk tas. Bambu yang dibending harus memiliki tebal yang sama rata, yaitu $2 \mathrm{~mm}$, dengan ketebalan $2 \mathrm{~mm}$ maka proses bending akan lebih mudah karena menghindari terjadinya patahan pada sudut yang dibentuk ketika bending dilakukan.

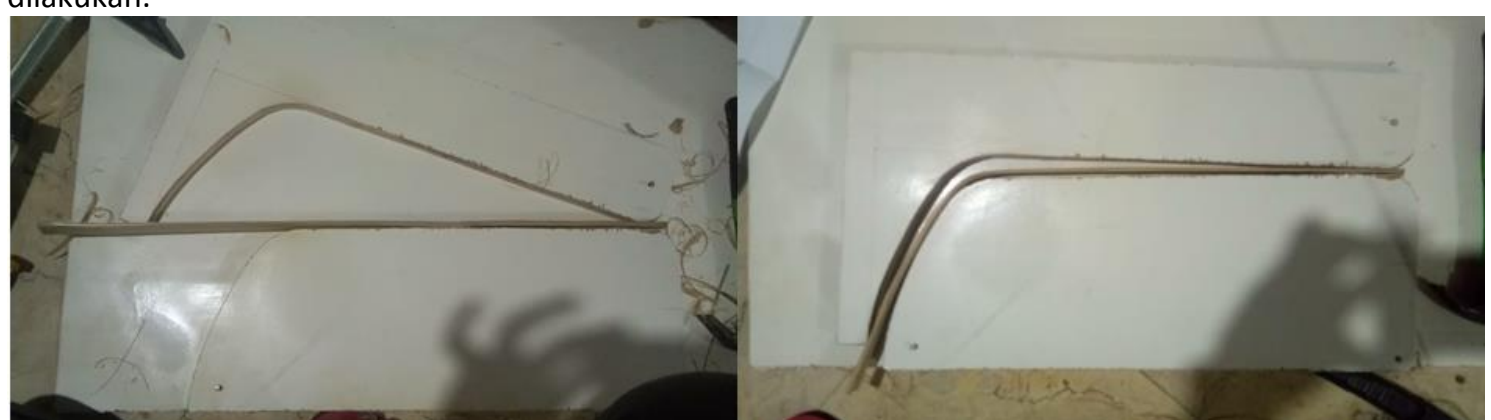

Gambar 7. Proses bending pada bambu
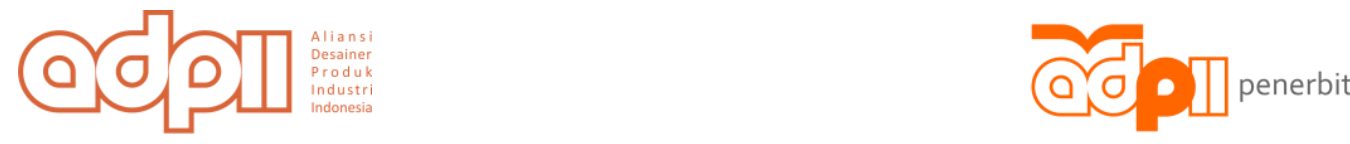

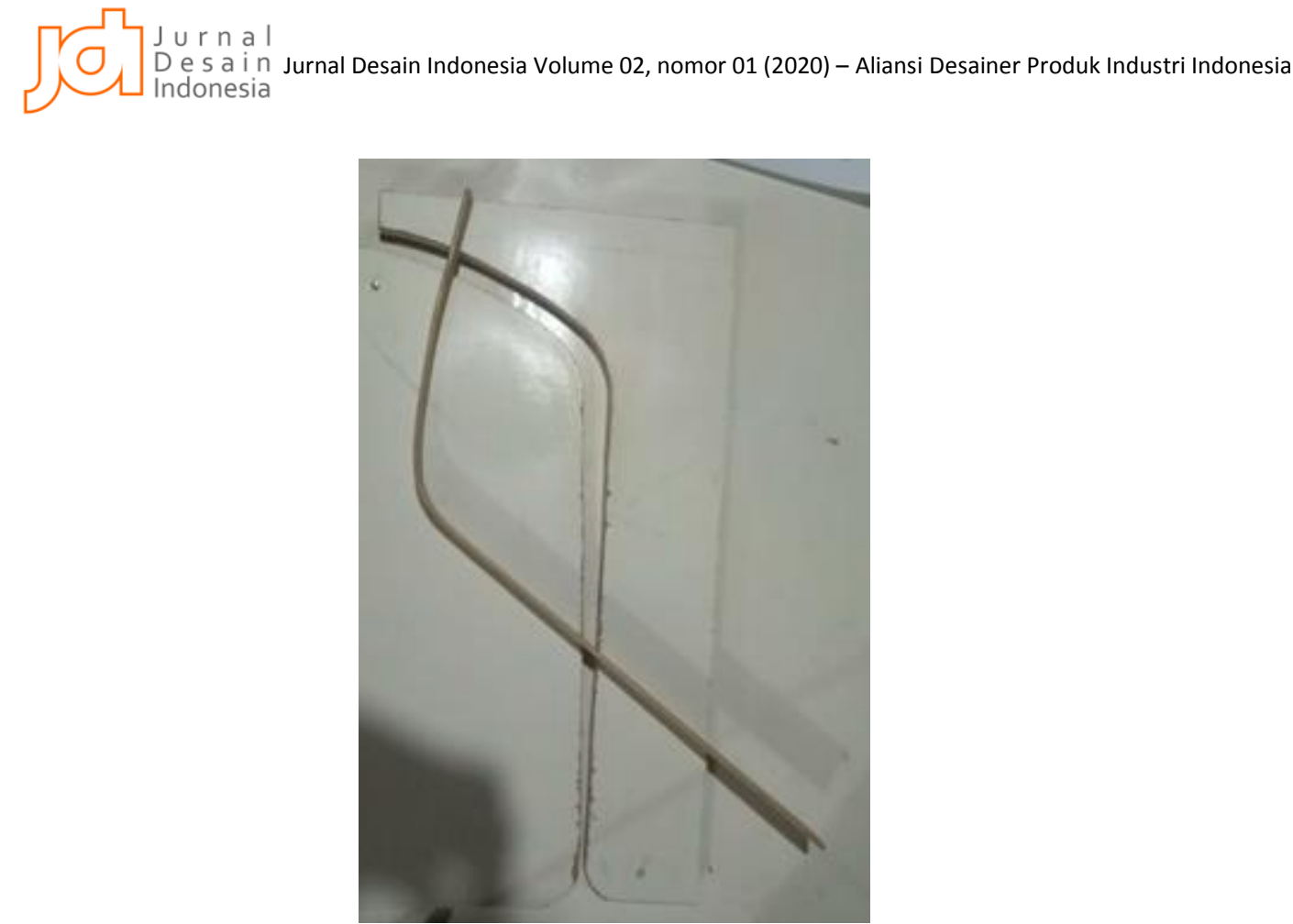

Page | 58

Gambar 8. Proses laminasi menggunakan molding

Setelah proses bending dilakukan proses selanjutnya yang dilakukan adalah proses laminasi yaitu dilakukan perekatan dengan menggunakan lem kayu yang selanjutnya dipress menggunakan molding yang dibantu dengan alat klem.
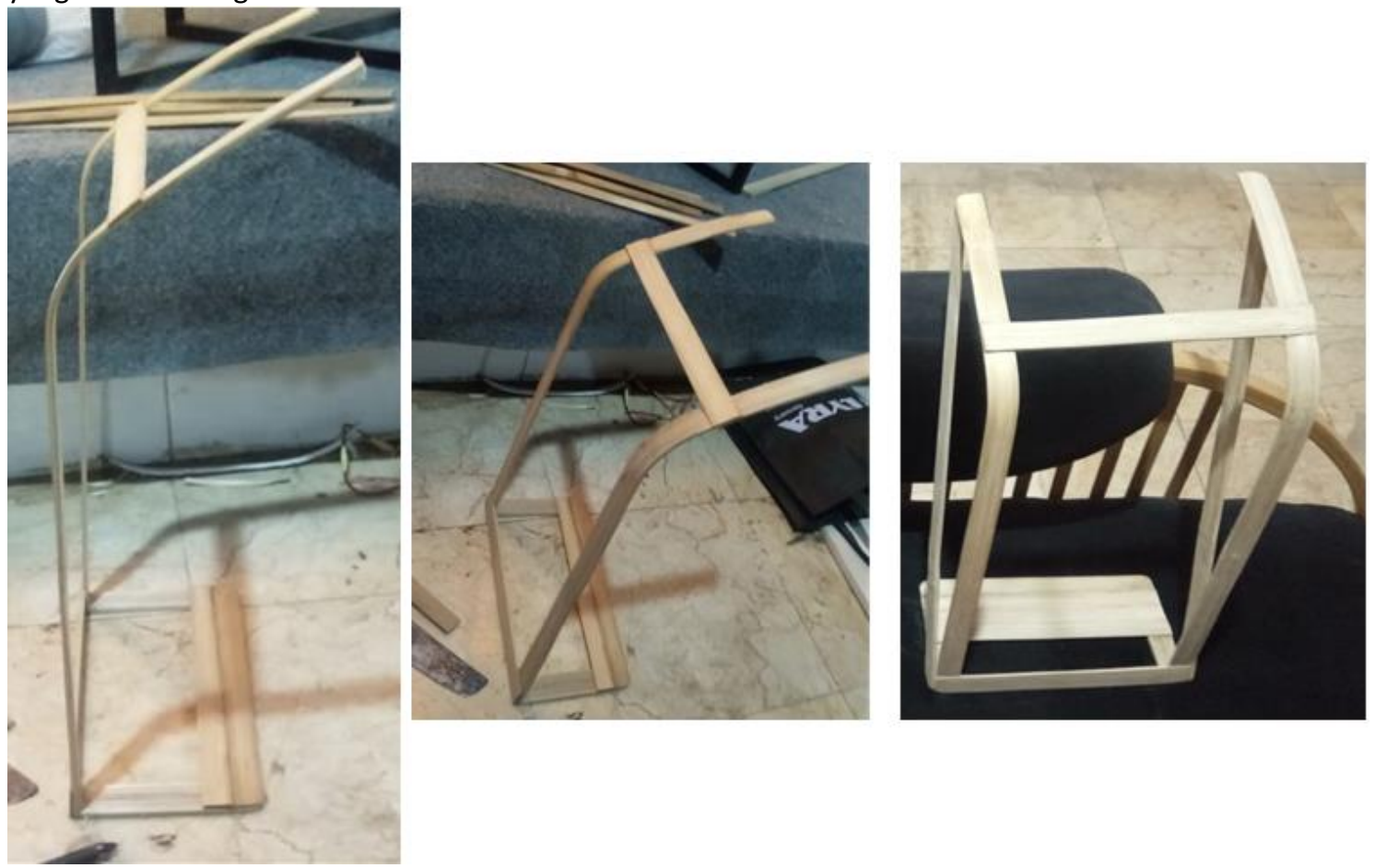

Gambar 9. Perubahan pada konstruksi tas dan tambahan struktur pada bagian samping konstruksi.

Setelah dilakukan assembly, penulis menguji coba konstruksi pada tas, akan tetapi terdapat masalah pada baigian konstrusi samping yang diuji. Yaitu kurang adanya rangka tambahan yang menopang konstruksi atas bagian samping. Penulis menambahkan konstruksi tambahan yang sanggup menopang dan menghubungkan konstruksi atas, bawah dan samping.
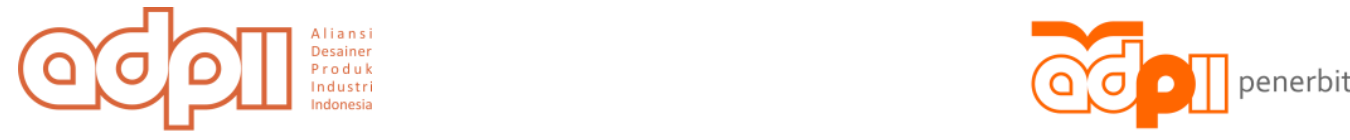

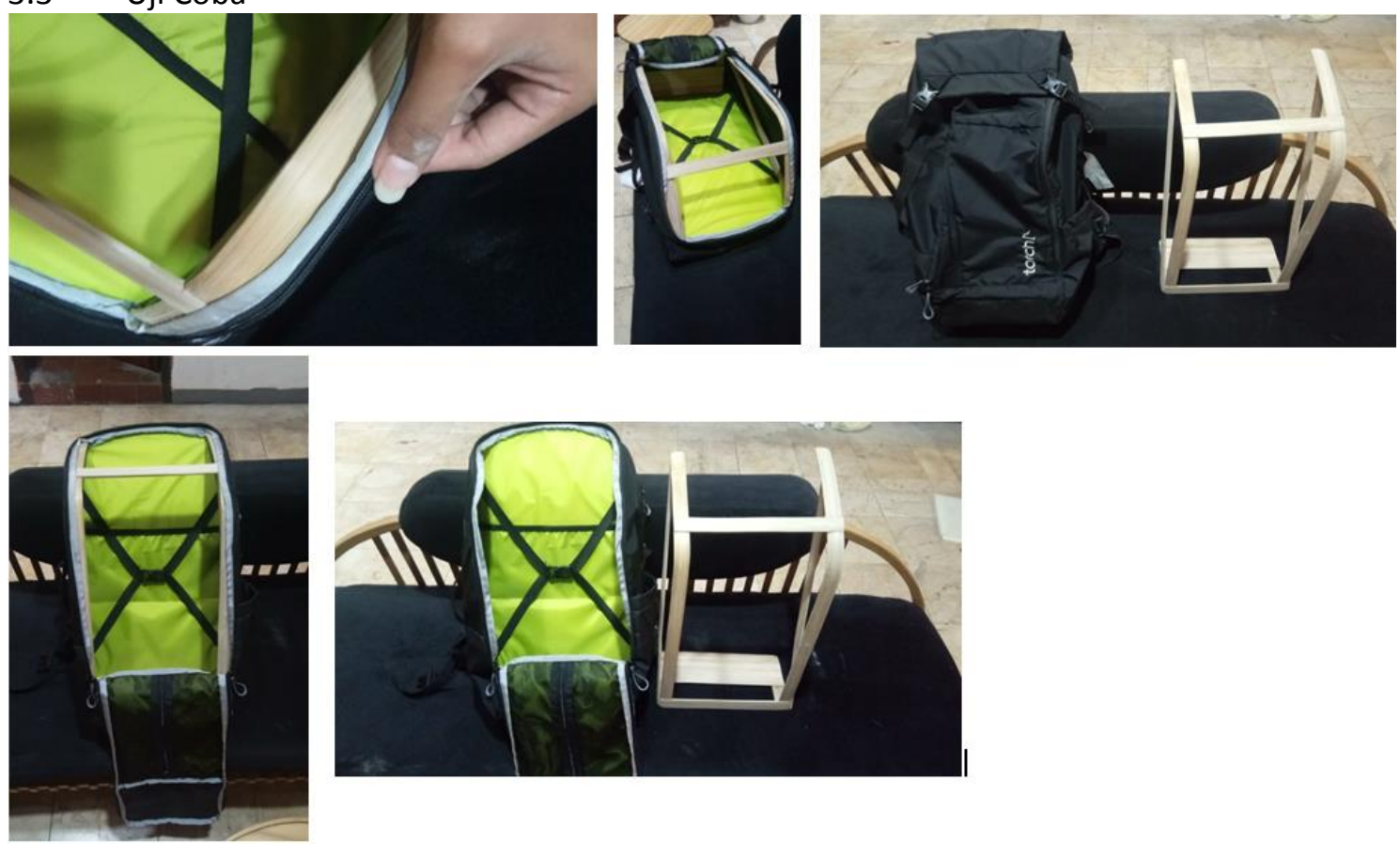

Gambar 10. Uji coba konstruksi dalam pada tas travel

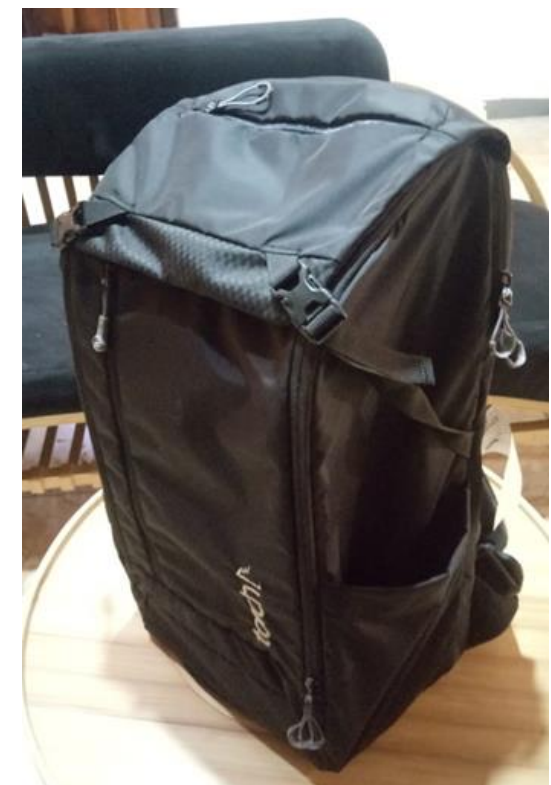

Gambar 11. Hasil bentuk tas travel yang diberi konstruksi pada bagian dalam

\section{KESIMPULAN}

Traveling menjadi salah satu hobi yang digemari masyarakat akhir-akhir ini. Tujuan melakukan traveling untuk beberapa orang sebagai refreshing memanfaatkan hari libur di sela sela kesibukan sehari-hari. Untuk menunjang aktivitas traveling dibutuhkan sarana bawa yang dapat memenuhi kebutuhan user. Sarana bawa untuk traveling antara lain Backpack, Koper,dan Duffel bag.

Pada umumnya pelaku traveling menggunakan Backpack pada setiap perjalananya karena dinilai praktis dan dimensinya tidak terlalu besar sehingga tidak mengurangi kenyamanan pada saat melakukan kegiatan traveling. Backpack travel pada dasarnya sama seperti daily Backpack hanya saja sebagian besar travel Backpack menggunakan system zipping 270 derajat agar memudahkan user saat packing barang bawaan ketika traveling. Selain system zipping,travel Backpack menggunakan bahan yang ringan
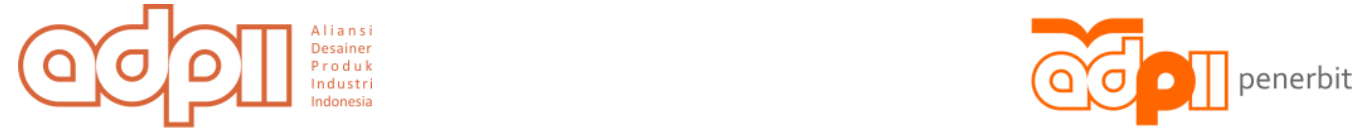
agar beban user berkurang di luar barang bawaan yang dibawa user. Akan tetapi dampak masalah yang muncul adalah bahan yang digunakan sebagai material utama menjadi tipis dan lunak sehingga dibutuhkan konstruksi.

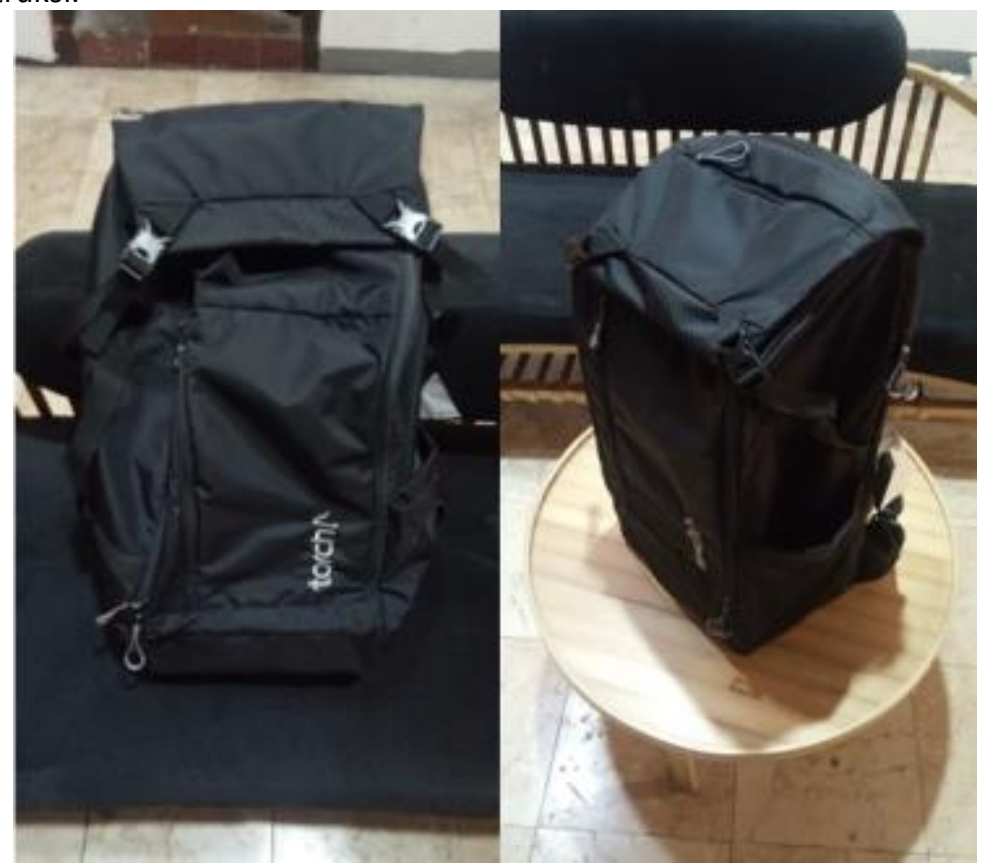

Gambar 12. Perbandingan travel Backpack sebelum dan setelah menggunakan konstruksi pada tas

Bambu memiliki potensi yang cukup besar sebagai material. Karena memiliki beberapa keunggulan diantaranya bambu dianggap material yang ekologis dan ekonomis. Bambu memiliki karakteristik yang kuat dan kokoh yang sangat mumpuni untuk dijadikan material konstruksi. Konstruksi dibutuhkan tas travel untuk memaksimalkan aspek fungsi. Penerapan bambu sebagai konstruksi pada sarana bawa dapat menjadi solusi untuk mempertahankan bentuk serta proteksi karena sifat serta karakteristik bambu yang mendukung. Akan tetapi bambu membutuhkan perawatan, sehingga aspek maintenance diperhitungkan pada kerangka, maka dari itu penulis dapat menyimpulkan bahwa konstruksi harus mudah untuk dilepas pasang.

\section{Referensi}

Arhamsyah. (2009). Jurnal Riset Industri Hasil Hutan . PENGOLAHAN BAMBU DAN PEMANFAATANNYA, $1(2), 30-35$.

Arsad, E. (2015). Jurnal Riset Industri Hasil Hutan. TEKNOLOGI PENGOLAHAN DAN MANFAAT BAMBU, 7(1), 45-52.

Heru, H. (2016). Jurnal Sosiologi. TRAVELING SEBAGAI GAYA HIDUP MAHASISWA YOGYAKARTA, 7.

Madhavi K, A. G. (1994). Bamboo Craft Design. Mumbai: IDC.

Masri, A. (2015, 10 15). Eksplorasi Material Bonggol Jagung Untuk Mendapatkan Nilai Kebaruan Pada Produk Kerajinan Kreatif. Seminar Nasional UNIBA Surakarta 2015, 7. Surakarta, Jawa Tengah, Indonesia: Seminar Nasional UNIBA Surakarta 2015.

Suriani, E. (2017). EMARA Indonesian Journal of Architecture. Bambu Sebagai Alternatif Penerapan Material Ekologis: Potensi dan Tantangannya, 3(1), 38.
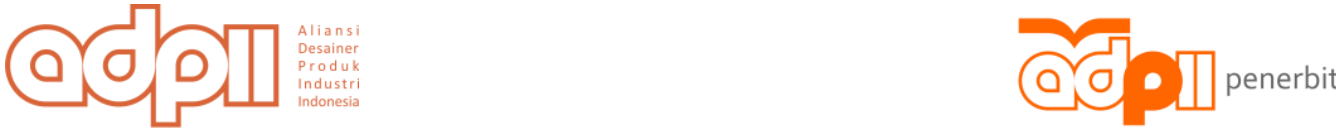